semester permit some students to expand their observational options to other communities.

Students visiting agencies during off-hours may see the repercussions of staff shortages or encounter the unexpected. One pair of students visiting a city court on a week-end viewed both arraignments and weddings. Another student, with limited time and transport wrote his paper about college financial aid applicants and the staff who responded to their needs.

\section{Dangers and Opportunities}

I have used brief field assignments for both lower and upper division courses, in day and evening classes, and in cities of various sizes. In every instance, I find that students learn from their own activities and from the observations of their classmates.
There is a danger that students may make erroneous generalizations from their brief field experiences. To rectify this problem, class members can be required to give short oral reports, comparing their impressions with peers who had similar experiences. Even a brief exchange contributes to class members' understanding of governmental processes.

Participants often refer to these field projects long after the end of the course. They describe their firsthand exposure as a highlight that enhanced their involvement with and understanding of class material.

\section{Reference}

Kendall, Jane C., John S. Duley, Thomas C. Little, Jane S. Permaul and Sharon Rubin. 1986. "Why Experiential Learning." In Strengthening Experiential Education within
Your Institution. Raleigh, North Carolina: National Society for Internships and Experiential Education. Reprinted from "A Nation at Risk: Another View," Experiential Education Newsletter, NSIEE, MarchApril, 1984.

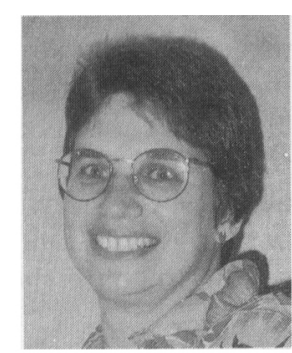
subsidized legal services.

\title{
Deconstructing the Other: Teaching the Politics of the Middle East
}

\author{
Mary Ann Tétreault, Iowa State University
}

Teaching comparative politics is an occupation with many built-in difficulties. First, there are problems not simply in choosing which cases to compare, but also in choosing the dimensions along which these cases will be compared. Second, the amount of information necessary to make interesting comparisons can be overwhelming, especially in an intercontinental region of more than twenty countries. For those teaching Middle Eastern politics, there is an additional difficulty: the perception among many American students that the Middle East and its people are irredeemably "Other," different in fundamental ways from every other population and culture in the world.

This sense of Middle Easterners as Other goes beyond perceiving them as exotic, and even beyond viewing them through the scrim of orientalism as described by analysts such as Edward Said (1979). It is equally the product of years of U.S. domestic politics and media coverage that have transformed what were once descriptive nouns and adjectives into reflexive, pejorative tropes: "Palestinian terrorist," "Iranian revolutionary," "Islamic militant," and many more. Etched in our brains by video footage showing military equipment, women in chadors, rioting crowds, and leaders in costumes, these pejoratives are chanted in presumably objective voiceovers emanating from putatively rational news analysts. Media reports not only mystify, they demonize, making it essential for the teacher of Middle East Politics to restore humanity to the population and combat the bias that often underlies Americans' understanding of Middle Easterners and their politics.

This discussion of strategies to overcome some of these difficulties is divided into three sections: boundaries, bases of information, and boredom. Throughout, I address the difficulties of teaching Middle Eastern politics and the problem of deconstructing the Other. In general, my approach is to emphasize similarities and commonality of interest, both among actors within the Middle East and between Middle Eastern leaders, businessmen, and citizens, and Americans in these same roles.

\section{Boundaries}

The question of boundaries is one that can be usefully incorporated directly into class material: what is the Middle East-and what is it in the middle of? Answers lead directly to a consideration of colonialism and the geopolitical construction of the Middle East according to the perspectives and objectives of western imperialists and statesmen-two categories with considerable overlap. ${ }^{1}$ These issues, in turn, spark discussions of ethnicity, religion, language, common histories, and they suggest 
subjective sense of relatedness and how these categories intersect with the historical effects of Ottoman and European imperialism. ${ }^{2}$

An approach that conceives of the boundaries of the subject as a problem in and of itself has many virtues. In the context of the Middle East, it introduces what will be an extensive consideration of the role of external intervention in domestic political and economic development. It lays the foundation for a later consideration of weak versus strong states, and differences between city-state politics and the more limited politics of relatively monocultural communities. ${ }^{3}$ Many students have been taught to view "democracy" and "participation" somewhat narrowly, so such a discussion is useful on a number of grounds. ${ }^{4}$ It connects domestic politics throughout the modern Middle East to the effects of great power intervention on civil societies that had evolved for centuries under conditions that had previously allowed domestic social groups to check, ameliorate, or evade state power and intrusion into civil life. 5

Boundaries also can be considered from the perspective of intra-regional divisions such as those separating oil-exporting, rentier, states from non-oil-exporting, presumably non-rentier states. I do not stress this particular distinction, in large part because I believe it to be overdrawn. In almost all Middle Eastern states, the state sector is by far the largest source of revenue. Virtually all of these regimes have "extraordinary power ... to preempt resources from actors outside the state system." (Richards and Waterbury 1990) Also, while it is true that some oil exporters have huge incomes as compared to their population bases, they by no means spend these incomes identically or with the same results. There are as many differences among oil exporters and among non-oil exporters as there are between these two groups.

Using the rentier state distinction in foreign policy analysis is also problematic. About half of my published research focuses on Middle East oil. Much of what I have read, seen, and thought about over the past twenty years leads me to believe that oil is not the only source of "ex- ternal" income for states in this region. Foreign aid, Suez Canal tolls, and remittances from nationals working abroad are similarly extracted from foreign sources and similarly exempt from norms of accountability in the context of domestic politics. ${ }^{6}$

Oil also is not a unique source of attraction for the degree and type of external intervention that I see as one of the defining characteristics of the region. Egypt, Algeria, and the Gulf emirates, for example, attracted intervention long before they became oil-exporting countries. The Middle East is economically and strategically important because of where and what it is-the land and sea bridges, along with their associated resources, connecting Europe to east and south Asia. This, after all, is why the region is called the "Middle" East.

Another common way to conceive intra-regional boundaries is to focus on divisions between Arabs and Israelis. This is another distinction that I believe is overemphasized and often used to support various political and, increasingly, religious agendas. I approach the subject by examining Israel as both similar to and different from other Middle Eastern states based on characteristics ranging from the history of external intervention and its impact on current international relations to religion and political culture, ethnic complexity, domestic politics, level of industrialization, and natural resource endowments. One can analyze the conflict between Israel and its surrounding Arab states in the same way that one analyzes other chronic conflicts in the region, such as the conflict between Iraq and Iran. Problems of Palestinian statehood can be compared to problems of statehood for the Kurds. A discussion of the various responses to both of these movements for national autonomy normalizes this issue in a constructive way and removes illusions that "justice" (and whose justice?) produces harmony.

\section{Bases of Information}

Students who register for courses in Middle East politics tend to fall into two main categories. The smaller category consists of persons with some prior experience and knowledge of the region. They take this course to learn more about a subject in which they are already interested. As a rule, these students begin and end with a larger and more complex knowledge base than their peers. These students are a gift in the classroom. They both confirm and challenge the information provided by text and teacher, and enrich it with stories based on their own experiences.

The majority of students, however, choose a course in Middle East politics because it fits into their schedules and/or meets departmental or university requirements for graduation. The size of this group varies depending on the salience of the Middle East during any particular semester. During the spring semester of 1991, which coincided with the conclusion of the Second Gulf War, sixty-eight students took my course on Middle East politics. That summer, I taught thirty-five students. In the fall of 1993, which featured an Israeli-Palestinian accord signed more than a month after the semester began, only eighteen students registered. In all three semesters, the number of students who came to the course after having studied or traveled to the region was three to five.

The most challenging part of teaching Middle East Politics is addressing the understandable ignorance with which most neophytes approach the subject. Looking at maps and discussing history, religion, and other aspects of culture and politics allows for progress but hardly begins to fill the void. Even students with prior knowledge of the Middle East and those who have traveled or lived there tend to be overwhelmed by the amount of information involved in surveying the region as a whole.

The best tactic is to choose a comprehensive main text, such as Politics in the Middle East (Bill and Springborg 1994), and supplement it with readings aimed at particular shortcomings in one's expected student population. For those with no background at all, a general reader such 
as the most recent edition of William Spencer's biennially prepared collection of summaries and popular articles, The Middle East, from the Dushkin Publishing Group, is useful. It is inexpensive, features maps, statistics, and photographs, and provides information about individual countries along with articles on various themes. More advanced students might benefit from a supplementary text focusing on theoretical issues. Among the best is Juan Cole's Comparing Muslim Societies (1992). It is a more difficult text, but the quality of the analyses and the comparisons they make are excellent. One of my students used models from this book to compare the etiologies of the Russian and Iranian revolutions.

I have also assigned a different main text, the Richards and Waterbury A Political Economy of the Middle East. I wanted to shift the students' focus away from the glamour of high politics and terrorism to bread and butter issues like water rights, oil revenues, population, and land reform. This worked well for the students who had taken introductory IPE and came with some prior knowledge of the region. However, most of the others found this text too difficult, not only because it included economic analysis, but also because it omitted important introductory materials on religion, politics, and domestic societies.

It may be helpful to choose a particular issue or country and examine it closely as a small case study. In spring 1991, for instance, I chose the Second Gulf War. Students read one of the "instant books" sold in supermarket check-out lines to capitalize on the widespread interest in the war, and they were required to read daily the New York Times. In the fall of 1993, I chose the Arab-Israeli conflict and we read Deborah Gerner's One Land, Two Peoples (1991) along with the daily New York Times. Spending three to four weeks on a single case enables one to concentrate on particular political issues and their antecedents, major actors and their relationships, and the international context in which the struggle and its resolution (or lack of it) are carried out.

\section{Boredom}

My first exposure to comparative politics was in graduate school, where I thought it was a boring series of hair-splitting arguments over meaningless issues carried out in dull texts devoid of pictures and conversations. I have since become an enthusiastic hair-splitter in arguments I now see as enthralling. As a feminist, I include conversations, if not pictures, in what I write, and I look for both in what I assign to my class. However, those early encounters comparing systems of proportional representation in industrial democracies or styles of corruption in southeast Asia have left me acutely aware of the likelihood that even my courses can produce glazed eyes, muffled snores in warm corners of the classroom, and tests that reveal a disappointing lack of awareness of the material covered in assigned texts.

The standard modern method for countering boredom is to include materials rich in sex and violence. This method works very well in courses on Middle East politics, although it is not without its problems. A more sedate but also effective approach is to assign materials that meet Alice's criteria-books and articles that look at real people (pictures!) in real situations (conversations!). Well chosen supplementary materials also provide an opportunity to examine prejudice explicitly, in the classroom and in the privacy of one's own mind, and serve as introductions to seeing behind façades.

Anti-boredom strategies include assigning biographies that discuss a particular country and people as well as describe a political regime and a set of problems that helped to shape a political career. Patrick Seale's (1989) biography of Hafez al-Assad lends itself well to classroom use. It is historical and contemporary, includes analyses of extraregional actors and events along with extended examinations of local and regional politics, and was completed in 1989 , thus allowing students to compare the author's predictions with actual outcomes and even to generate new predictions from the general conclusions he drew.

Readings with sex and/or violence are plentiful. One semester I confronted stereotyping by assigning sections of Said's Orientalism (1979) and Paul Bowles's novel, The Sheltering $S k y$, which was released that season as a feature film. Orientalism is difficult reading, but joining these two texts produced what I would call an epiphany in the classroom. The Sheltering $S k y$ is profoundly orientalist on one level (it is filled with flies, dirt, and exploitive sex) and, after reading Said, most students were able to find multiple examples of orientalism in its construction. The epiphany came when we talked about how it is also "occidentalist." The author, extolled on the cover as a voluntary exile in the land of the Other, repudiated his own culture's values even as he took its prejudices with him.

Sex can be introduced in a less steamy way: as gender and gender politics. Imperialists elevated the veil to a position of cultural primacy by depicting their activities in the Middle East as the rescue of oppressed native women. Ever since, westerners have been obsessed by the veil and its collective manifestation, the harem. ${ }^{7}$ Most students are eager to penetrate the "secrets" of family life and gender relations in the Middle East and look forward to readings on this theme.

The book that has had the greatest influence on my students is B. J. Fernea's Guests of the Sheik (1965). Written by a new bride set down in a strange place, this book had the power to humanize Iraqis during the Second Gulf War and it perennially draws students of both genders to choose the Middle East as a subject of further study. Part of its magic comes from the ready-made interest in the topic and the acuteness of Fernea's observations. However, I think that its greatest charm lies in the author's willingness to expose her ignorance and uncertainty and to reveal the stages of her understanding of what she was learning. By appearing to the reader as a student herself, the barrier between the author who knows and the reader who must be informed is never encountered. The effects of modernization on traditional societies are described as a universe rather than set down as a list, helping students to see the 
connections among variables. The book also allows a class to discuss polygyny, female seclusion, clientelism, Islamic religious practices, and other potentially "exotic" topics in the same terms one would use to discuss family life, employer-employee relations, and religious practices in Virginia or Iowa.

I assigned Philippa Strum's The Women are Marching (1992) as a supplement during a semester when I chose the Arab-Israeli conflict as a case study. Students came to this book with some knowledge of the political situation though few knew much about gender issues among Israelis or Palestinians. The Women are Marching disturbed some students, partly because it personalized the violence they are more comfortable reading about when it is presented as "political science" in books like One Land, Two Peoples. Family problems presented in this book were also more disturbing to students than the problems discussed in Guests of the Sheik. It would not surprise me to hear that some of the students' own families experienced the same conflicts over what is proper behavior for young women or what sorts of people young men should be hanging around with.

Another reason why this book may have upset readers is that Strum's prediction for the community she studied is bleak. In contrast, Fernea's speculations about the future are more optimistic. Even though each book was read during a period featuring the deaths of individuals and destruction of the communities the students were reading about, the differences in projected outcomes allowed students to remain optimistic about the fates of Fernea's characters as they could not be about Strum's.

Tom Friedman's From Beirut to Jerusalem (1989) is a favorite among students as well as uncoerced readers. The virtues of this book go beyond its being a page-turner. It compares the political culture of Israel to that of a neighboring Arab state and examines the political economy of violence in this volatile region as a systemic phenomenon.

The book's shortcomings are reminiscent of Paul Bowles's troubles drawing the line between us and them. Friedman has sympathy for Lebanon, a country that interests him, but he has empathy for Israel. His profound sense of belonging to Israel is rooted in his summers as a teenager working on a kibbutz. It is infused with all the idealism and romance of such an experience for a child from a secular Jewish family who discovers his cultural roots on his own. Friedman's stated thesisthat political violence in Israel and Lebanon has similar individual, social, and environmental bases-is overridden by an unstated belief that Arab violence is less rational than Israeli violence, an assumption revealed most clearly by the author's emotional reaction to a stone thrown at a car carrying him and his family.

From Beirut to Jerusalem also illustrates the perils of the sex-and-violence strategy to keep students interested. Many come away from Friedman's book confirmed in their original conviction that the Middle East is a violent place populated by crazy people. A similar unanticipated result came from the assignment of Kanan Makiya's book, The Monument (1991). I wanted to show how Iraq is similar to Nazi Germany and the Soviet Union in the pervasiveness of totalitarian control. However, students who read The Monument and chose an essay question I offered them on art and politics on the final exam demonstrated that they really learned that the Middle East is a violent place full of crazy people. They wrote in lavish detail about the man who drew pictures of Saddam using his own blood more than about any other point made in the book or in class. The monument of which the title speaks is cast from a model of Saddam's own right arm rising out of a base of genuine Iranian helmets possibly containing corporeal residues of their former owners. In these student essays, descriptions of this monument were nearly as frequent as comments on the portraits in blood.

Most of the books described in this section are assigned to subsets of students who are asked to use them as foundations for individual essays and group oral reports. Splitting a syllabus expands the range of information and perspectives represented without making everyone (other than the instructor) read every single thing. It also lures students to do more than is specifically required of them.

I also invite theatricality in the oral reports. The most innovative presentation was made by a group that discussed The Sheltering Sky in costume and with props-an oriental carpet, a tent cushion, what looked like someone's grandmother's trunk, and appropriate music on tape. However, I have found that a row of students saying seriatim, "Wow, this was a really great book," can accomplish much the same result.

Given Alice's prediliction for pictures and conversations, the careful reader might wonder why I rarely show films or videos in this course. In general, I believe these to be media for passive learning. When my children were young, I limited the amount of time they could watch television. I am committed to encouraging reading, writing, and conversation over "viewing" among my students, especially in large courses where discussions are limited. I do on occasion show slides in class, in the process inviting comments and challenging students to imagine what lies beyond the frame projected on the screen.

\section{Autonomy and the Other}

Near the end of a semester that included the Arab-Israeli conflict as a case study and From Beirut to Jerusalem, The Monument, and The Women are Marching as supplement choices, my students complained that the course was depressing. They were right: Three classes before the end, I tossed the rest of the syllabus and resolved to show the Middle East as the home of actors, not just the acted upon. I began with the corporate strategy of the Kuwait Petroleum Corporation (KPC). Its multinational vertical integration gave Kuwaitis strategically located economic, geographic, and political bases from which to operate during the Iraqi occupation, as well as liberating them from dependence on raw materials sales to third parties as their primary source of national income and foreign exchange.

The Kuwaiti women's movement 
was a more ambiguous topic because its successes remain limited. This is why I tried to counter the tendency to imagine a bleak future by comparing the women's movement in Kuwait to the "first wave" of the women's movement in the United States. These movements share a number of similarities. Comparison perforated the line between $u s$ and them by disclosing those similarities, and allowed the students to project their overall optimism about the future for gender equality in the United States onto their perceptions of what might lie ahead for Kuwaiti women.

Otherness is not simply the result of orientalist thinking, demonizing politics, or unreflective reporting. It comes from insufficient thought and the insufficiency of comparative models that stress relationships and common interest. As social scientists, we tend to concentrate on problems and conflicts in our research and policy recommendations. But considering a region solely in terms of its problems is inherently objectifying. This approach denies agency by conveying an impression of inevitability, and thereby denies individuality and a human identity to the people who live there.

Hannah Arendt (1959) tells us that our individuality-in her term, our "plurality"- enables us to be political, and that it is politics that makes us fully human. It is critical to introduce students to Middle Easterners in a way that highlights the "essential human condition of plurality, the acting and speaking together, which is the condition of all forms of political organization." Presenting the Middle East and its people as political agents who-like us - are proceeding to an undefined future, conveys an understanding of this re- gion as a living system rather than as a stereotype of immutable, exotic otherness.

\section{Notes}

1. These connections can be inferred from travel literature and the writings of the imperialists themselves. One of my favorite volumes from an imperialist is H. R. P. Dickson's Kuwait and her Neighbours (London: Allen \& Unwin, 1956). The connections are made explicitly by the histories of individual countries and the region as a whole during and after the first world war. See, for example, Phebe Marr's The Modern History of Iraq (Boulder: Westview Press, 1985); and David Fromkin's The Peace to End All Peace: The Fall of the Ottoman Empire and the Creation of the Modern Middle East (New York: Avon Books, 1989).

2. Some of these issues are discussed in the context of the disintegration of Yugoslavia in Misha Glenny, The Fall of Yugoslavia: The Third Balkan War (New York: Penguin, 1992), especially chap. 1 . Others are treated in Fromkin, $A$ Peace to End all Peace.

3. See, for example, Joel S. Migdal, Strong Societies and Weak States: State-Society Relations and State Capabilities in the Third World (Princeton: Princeton University Press, 1988); Patricia Springborg, "Politics, Primordialism, and Orientalism: Marx, Aristotle, and the Myth of the Gemeinschaft," American Political Science Review 80 (March 1986).

4. The evolution of "democracy" into "republicanism" is treated at length in Patricia Springborg, Western Republicanism and the Oriental Prince (Austin: University of Texas Press, 1992).

5. See, for example, Mary Ann Tétreault "Autonomy, Necessity, and the Small State: Ruling Kuwait in the Twentieth Century," International Organization 45 (Autumn 1991); or Mark J. Gasiorowski, U.S. Foreign Policy and the Shah: Building a Client State in Iran (Ithaca: Cornell University Press, 1991).

6 . These are some of the characteristics associated with rentier income-see, for example, Giacomo Luciani, "Allocation vs. Production States: A Theoretical Framework," and Hazem Beblawi, "The Rentier State in the Arab World," both in The Arab State, ed. Giacomo Luciani (Berkeley: University of California Press, 1990).

7. Imperialism and the discourse of the veil are wonderfully analyzed in Leila Ahmed's
Women and Gender in Islam (New Haven: Yale University Press, 1992), pp. 145-55. A discussion of the role of the harem in colonial discourse can be found in Malek Alloula, The Colonial Harem, trans. Myrna Godzich and Wlad Godzich (Minneapolis: University of Minnesota Press, 1986).

\section{References}

al-Khalil, Samir (Kanan al-Makiya). 1991. The Monument: Art, Vulgarity and Responsibility in Iraq. Berkeley: University of California Press.

Arendt, Hannah. 1959. The Human Condition: A Study of the Central Dilemmas Facing Modern Man. Garden City: Doubleday Anchor.

Bill, James A. and Robert Springborg. 1994. Politics in the Middle East, 4th ed. New York: HarperCollins.

Cole, Juan R. I. ed., 1992. Comparing Muslim Societies: Knowledge and the State in a World Civilization. Ann Arbor: University of Michigan Press.

Fernea, Elizabeth Warnock. 1965. Guests of the Sheik: An Ethnography of an Iraqi Village. New York: Anchor.

Friedman, Thomas L. 1989. From Beirut to Jerusalem. New York: Doubleday Anchor.

Gerner, Deborah J. 1991. One Land, Two Peoples: The Conflict Over Palestine. Boulder, CO: Westview Press.

Richards, Alan and John Waterbury. 1990. A Political Economy of the Middle East: State, Class, and Economic Development. Boulder: Westview Press.

Said, Edward W. 1979. Orientalism. New York: Vintage Books.

Seale, Patrick. 1989. Asad of Syria: The Struggle for the Middle East. Berkeley: University of California Press.

Strum, Philippa. 1992. The Women are Marching: The Second Sex and the Palestinian Revolution. Brooklyn: Lawrence Hill Books.

\section{About the Author}

Mary Ann Tétreault is the author of The Kuwait Petroleum Corporation and the Economics of the New World Order, and co-director of the Barbara Chasan Center for Creative Approaches to Social Change. She teaches political science at Iowa State University. 